\title{
Discurso governamental e inclusão digital: a luta de classe metaforizada
}

\author{
Government discourse and digital inclusion: the class \\ struggle metaphorized
}

\section{Hemanuel Jhosé Alves Veras}

\begin{abstract}
Mestrando do Programa de Pós-Graduação em Ciências da Comunicação (PPGCCOM) da Universidade Federal do Amazonas (UFAM), bacharel em Administração Pública pela Universidade do Estado do Amazonas (UEA) e em Comunicação Social Jornalismo pela Universidade Federal do Amazonas (UFAM), Manaus, AM - Brasil, e-mail: hemanuel.veras@gmail.com
\end{abstract}

\begin{abstract}
Resumo
O presente artigo objetivou analisar o funcionamento do discurso governamental a respeito da inclusão digital presente em um texto publicado no Blog do Planalto. A metodologia utilizada foi a análise do discurso da linha francesa, buscando identificar uso da linguagem, as formações discursivas e as formações ideológicas presentes no texto produzido pela assessoria de comunicação da presidência da república. Para tanto, são apresentados dois panoramas teóricos: o primeiro a respeito da inclusão digital e o segundo sobre a teoria da análise do discurso. A partir dessas fundamentações e da metodologia utilizada, a análise revelou que o discurso governamental está atrelado ao sentido de uma luta de classes, em que os programas de inclusão digital, promovidos pela gestão federal, posicionam-se a favor das classes necessitadas. Outras conclusões indicaram que o significado de inclusão digital presente no texto ainda está muito restrito apenas à disponibilização da tecnologia, e que essa irá servir apenas para informar e não para promover a interlocução e a comunicação dos cidadãos.
\end{abstract}

Palavras-chave: Inclusão digital. Análise do discurso. Cibercultura. 


\begin{abstract}
This paper aims to analyze the functioning of the government discourse on digital inclusion through a text published in "Blog do Planalto" internet blog. The methodology used was the French line discourse analysis, seeking to identify the use of language, the discursive and ideological formations in the texts produced by the press office of the presidency. For that purpose two theoretical overviews are presented: the first overview is on digital inclusion and the second one lies on the theory of discourse analysis. From these foundations and with methodology used, the analysis showed that the government discourse is tied to a sense of class struggle in which the digital inclusion programs - promoted by the federal administration - intend to help the needy classes. Other conclusions indicated that the meaning of the digital inclusion present in the texts is still very restricted to the availability of technology and that it would only serve to promote information and not to promote dialogue and communication between and from citizens.
\end{abstract}

Keywords: Digital Inclusion; Discourse Analysis; Cyberculture.

\section{Introdução}

A inclusão digital entrou na agenda política brasileira. A preocupação dos governos em incluir a população na vida digital tem se mostrado presente tanto nas políticas públicas implementadas por diferentes gestões, como também durante a eleição para presidente e para governadores brasileiros em 2010.

Essa preocupação não é nova nos países latinos. Os dados registrados hoje indicam que a América Latina e a África ainda são regiões onde grande parte das populações não tem acesso às tecnologias de informação e comunicação (TICs), como a internet.

Rifkin (2001) considera o acesso às tecnologias da comunicação como sendo tão importante hoje como foi o acesso à propriedade nos séculos passados. Para ele e para outros pesquisadores da cibercultura, ${ }^{1}$ as questões da propriedade discutiam o que era "meu" ou "seu", mas as questões do acesso discutem "quem" tem acesso e controla as experiências vividas.

As diferenças de estrutura de comunicação entre os países desenvolvidos e aqueles que ainda estão em desenvolvimento divide o mundo entre os que têm acesso à informação e os que não têm.
A maior parte da população dos países em desenvolvimento não tem acesso à produção cultural, à informação em rede e à comunicação multidirecional proporcionadas pelo ciberespaço. ${ }^{2}$ Estão, portanto, excluídas de toda a discursividade a ela relacionada.

Em todo mundo governos e instituições buscam auxiliar as populações a serem inclusas nesse novo meio de comunicação. Mas, o sentido de inclusão digital trabalhado nesse contexto não é o mesmo em todas as iniciativas. Para explicitarmos qual desses sentidos é utilizado pelo governo brasileiro vamos analisar um texto do Blog do Planalto a respeito dos programas governamentais que trabalham a temática.

A metodologia utilizada será a Análise do Discurso da linha francesa e terá como objetivo revelar os dispositivos que fazem funcionar o sentido de inclusão presente nos textos do governo. Para compreendermos melhor essa temática iremos recapitular a relação entre o ciberespaço, a política e a inclusão digital, bem como entre a sociedade e a linguagem.

Por fim, realizaremos a análise do corpus já citado, buscando compreender a ideologia e os esquecimentos atuantes no sentido de inclusão que o governo brasileiro compreende.

\footnotetext{
1 Cibercultura é o termo que segundo Lévy (1999, p. 17), "especifica o conjunto de técnicas (materiais e intelectuais), de práticas, de atitudes, de modos de pensamento e de valores que se desenvolvem juntamente com o crescimento do ciberespaço".

O ciberespaço é o novo meio de comunicação que surge da interconexão mundial dos computadores.
} 


\section{Ciberespaço, política e inclusão digital ${ }^{3}$}

Com a evolução causada pela internet nas formas de comunicação, a inclusão digital passou a se relacionar diretamente aos direitos básicos à informação e à liberdade de expressão. Daí sua atual referência política:

a exclusão digital é uma das muitas formas de manifestação da exclusão social. Num momento em que empresas e governos migram informações e serviços para os meios eletrônicos, o excluído digital passa a ter dificuldade de conhecer e exercer seus direitos de cidadão (CRUZ, 2004, p. 13).

Apesar do ciberespaço não ser físico, ele é ponto de encontro de milhões de pessoas que, juntas, podem construir nova formas de compreensão do mundo que não estão ao alcance de todos. A comunicação em rede aprimora a interação entre as pessoas, possibilita um comércio eletrônico, a criação de significados compartilhados e o engajamento em questões globais.

Dessa forma, as redes de comunicação presentes no ciberespaço tornaram-se importantes na organização e comunicação e atividades em toda sociedade. Os movimentos sociais e políticos também estão se apropriando dessa poderosa ferramenta cada vez mais, buscando agregar forças, organizar-se e dar expressão aos seus anseios (CASTELLS, 2003,p. 114).

O ciberespaço proporciona a produção livre e colaborativa, aumentando possibilidades para obter informações a partir das mais diversas fontes. Essa transformação proporciona ao cidadão uma série de escolhas até então impossíveis por conta dos modelos de comunicação existentes.

A World wide web, em especial, possibilita a produção e distribuição de conteúdos para qualquer usuário, graças à sua interface gráfica acessível a todos. "Não se trata apenas de uma diferença de grau, mas de uma mutação na natureza do espaço de comunicação, de um salto da inteligência coletiva humana" (LEMOS; LÉVY, 2010, p. 63).
Entretanto, há uma correlação direta entre desenvolvimento econômico e a exclusão. Se o desenvolvimento econômico e político desse novo século passam pelo domínio das tecnologias da informação e da comunicação, os excluídos desse processo passarão a ser excluídos da vida econômica e política da sociedade (CRUZ, 2001).

Buscando garantir a inclusão das populações, foram promovidos em todo mundo programas governamentais ou privados motivados pela iniciativa de incluir as pessoas digitalmente. Segundo Warschauer (2006), o problema dessas iniciativas é que grande parte delas tem uma compreensão restrita do conceito de inclusão e, portanto, de exclusão digital. A utilização inicial do sintagma "inclusão digital" atribuiu demasiada importância aos aspectos de disponibilidade física e não ao conteúdo, língua, educação ou recursos comunitários, que, necessariamente são constitutivos do conceito.

Mesmo que se pense no sentido mais amplo dessa exclusão, ainda é necessário compreender que a falta de acesso à internet reduz as oportunidades de melhoria de vida, mas que inverso também é verdadeiro. Por conta disso, Warschauer (2006) contrapõe ao fenômeno da exclusão digital a inclusão social, que reconhece o conjunto de variáveis que moldam a interação social.

As formas mais comuns de permitir o acesso das pessoas às novas tecnologias são os modelos baseados em equipamentos e conectividade. No primeiro, as iniciativas preocupam-se apenas em disponibilizar os equipamentos de informática. No segundo, surge a preocupação de fornecer uma conexão regular às pessoas.

O crescimento do acesso da população a esses fatores evidencia que não é somente a disponibilidade de equipamentos e conexão que inclui o indivíduo digital ou socialmente. Essa inclusão só ocorre por meio da capacidade do usuário de fazer uso desses componentes em práticas sociais significativas. Essa prática inclusiva é bem próxima do modelo educacional de letramento (WARSCHAUER, 2006, p. 64).

O letramento digital passa necessariamente pelo uso social do aparato digital. Uma inclusão digital

\footnotetext{
Por inclusão digital entendemos a definição de Cruz (2004): "é a apropriação e o acesso às tecnologias da comunicação e da informação de forma consciente".

O letramento é a prática de ler e escrever levando em conta fatores sociais, culturais e econômicos (WARSCHAUER, 2006, p. 60).
} 
que se proponha a realizar essa prática leva em conta os recursos físicos (equipamentos, ferramentas), digitais (conteúdo, língua do conteúdo), humanos (letramento, educação) e sociais (organização comunitária, instituições) para apropriação da internet e demais tecnologias de informação e comunicação.

Logo, uma iniciativa contrária à exclusão digital implica em apropriação da tecnologia de forma consciente que, de fato, promova a inclusão social. O usuário deve decidir sozinho quando, como e para quê utilizará a tecnologia. Se esse processo ocorre sem estar relacionado ao desenvolvimento pessoal e comunitário, deixa-se de abarcar uma dimensão histórica, política, ética e cidadã (CRUZ, 2004, p. 10).

O grande problema das iniciativas de inclusão sociodigital realizadas pelo governo ou por organizações não governamentais é a falta de compreensão dessa dinâmica. As ações levam em conta apenas os recursos físicos ou digitais. O ponto de partida não deve ser apenas a superação da exclusão digital, compreendida somente como infraestrutura, mas a maneira como os meios digitais podem auxiliar e fortalecer as estruturas sociais já existentes.

Faz-se importante nesse sentido avaliar de qual forma os governos compreendem o processo de inclusão digital e que consequências isso gera para as políticas públicas que essas gestões implementam. Um caminho possível para tal tarefa é analisar quais são as filiações ideológicas presentes nos textos divulgados dessas gestões, dando sentido aos possíveis sentidos de inclusão que elas trabalham.

Para se chegar a tais filiações é necessário antes compreender os discursos que se encarregam de materializá-las nesses textos. Precisa-se entender os mecanismos que formam esses discursos e os colocam em circulação. É o que discutiremos.

\section{Linguagem e sociedade}

A Análise do Discurso (AD, doravante) é uma disciplina de entremeio. É uma teoria científica localizada entre os estudos da linguística, que tem como objeto o estudo da língua, e as ciências sociais, que trabalham as relações sociais a partir de conflitos ideológicos (SOUZA, 2006, p. 15).

Tal teoria busca tornar possível, a partir de seus pressupostos, um acesso às filiações ideológicas em que os sujeitos estão inscritos. Os sujeitos agem de acordo com os dispositivos ideológicos que lhe constituem, não se dando conta de como são constituídos por esses pressupostos. $\mathrm{O}$ analista, por sua vez, se propõe a um afastamento da linguagem para analisar o discurso da alteridade, agindo por meio do dispositivo teórico.

Entretanto, essa análise não nega os dispositivos ideológicos que constituem o próprio analista. Ela os aceita e busca fortalecer a avaliação do pesquisador por meio do fortalecimento do dispositivo teórico existente. Para compreendermos essa teoria faz-se necessário compreender as contribuições que ela recebeu ao longo da história.

Um termo de grande importância para a AD é ideologia. Para Marx, a ideologia é o conjunto de ideias que a classe dominante propaga para manter controle sobre a classe dominada (MARX, 1998). Por conta disso, se diz que em Marx a ideologia é a distorção da realidade social intencionada pela classe dominante, que a utiliza como mecanismo de controle e dominação.

Esse conceito marxista é resgatado por Althusser (1996). Esse autor propõe que o Estado é o mantenedor dessa ordem social repressora, criando o Aparelho Repressivo do Estado, composto dos tribunais, da polícia e dos presídios, e os Aparelhos Ideológicos do Estado, como a religião, a escola e o sistema de informação (SOUZA, 2006, p. 51).

Outro teórico que contribuiu sobremaneira com a questão da ideologia, como se entende na AD, foi Foucault $(2007,2009)$. Segundo esse teórico, as relações de poder na sociedade não se restringem apenas à relação entre classe dominante, Estado e classe dominada, mas sim a uma série de mecanismos invisíveis que tornam os sujeitos assujeitados a múltiplos cerceamentos. Esses cerceamentos tomam a forma que a sociedade impõe por meio de modelos de relação, como na relação professor e aluno, por exemplo.

Foucault criticou a teoria marxista argumentando que a economia não é determinante no que é dito ou pensado em uma época. Para ele, a economia é uma "inter-relação complexa entre as estruturas sociais, estruturas econômicas e o discurso, sendo que nenhum desses elementos da relação é dominante" (SOUZA, 2006, p. 62).

Quanto à teoria althusseriana, Foucault critica a noção de que a ciência se encontra fora da ideologia, podendo assim analisá-la em toda 
sociedade, mas estando isenta dela. Para Foucault, até mesmo os cientistas são influenciados por um conjunto de ideias, por serem determinados por questões discursivas, institucionais e sociais.

A linguagem é pensada por Foucault como o lugar onde as lutas de poder acontecem, o poder do qual os indivíduos querem se apropriar. Ao falar de discurso, o autor enfatiza que uma análise dessas estruturas discursivas não deve ser realizada para revelar verdades, mas sim para evidenciar os mecanismos que tornam sua circulação possível em determinada época.

Cada período histórico tem uma episteme, um sistema de discursos a partir do qual cada cultura pensa. O sujeito que vive imerso em determinada estrutura não reconhece que seus pensamentos são direcionados por essa episteme. Por exemplo, um homem que viveu no Brasil durante o século XVIII poderia discursar em praça pública sobre a inferioridade das pessoas negras sem ter o efeito de politicamente incorreto. Essa crença e os sentidos relativos a ela faziam parte da episteme de seu contexto histórico-social em que a questão racial era configurada de outra forma.

Hoje as pessoas considerariam esse comportamento inaceitável e preconceituoso. Tanto as pessoas do século XVIII como de hoje não se dão conta que essas ideias fazem parte da episteme de suas épocas. Por estarem imersos, consideram suas crenças e comportamentos normais e aceitáveis.

São as regras desses enunciados e os limites que eles obedecem que interessavam a Foucault. O teórico estudou o ordenamento dos enunciados e o porquê de alguns deles serem excluídos. Nesse sentido criou a noção de arquivo, que é o conjunto de mecanismos que limita o que pode ser dito ou lembrado (SOUZA, 2006).

Os autores apresentados até aqui trabalharam a relação da linguagem com as questões sociais de forma não integrada. $\mathrm{O}$ primeiro pensador que articulou esse conhecimento em uma teoria foi Pêcheux. De forma geral ele buscou correlacionar a questão do discurso com a do sujeito e a ideologia (PECCHEUX, 1998).

Inicialmente Pêcheux procurou deslocar as ciências sociais apoiando-se na releitura que Althusser fez de Marx e que Lacan fez de Freud. Uma das primeiras concepções trabalhadas é de que o sistema da língua determina o sujeito dos discursos e não os sujeitos que determinam seus próprios discursos. O sujeito na AD é assujeitado: o sistema não determina o discurso que ele enuncia, mas restringe suas possíveis escolhas por meio da ideologia de sua época.

A teoria, entretanto, ainda apresentava dificuldades em relacionar esses discursos à história. Por conta disso resgatou-se o conceito foucaultiano de formação discursiva (FD). A FD é um conjunto de regras históricas que num determinado contexto definem a condição do uso dos discursos. São essas formações que balizam o que pode ser dito e a partir de que lugar de fala que o sujeito ocupa.

Assim, uma FD é marcada por regularidades (regras de formação) que funcionam como mecanismos de controle (internos e externos, segundo Foucault) que determinam o que lhe pertence e o que não lhe pertence. Esses mecanismos mostram que o que se diz não provém de uma infinitude de significados, mas de condições de possibilidades de dizer específicas (SOUZA, 2006, p. 89).

É necessário ressaltar que tais formações discursivas se definem pela alteridade entre si e que são atravessadas umas pelas outras dentro dos discursos. Logo as FDs não são estáveis e heterogêneas, mas sim dispersas e entrelaçadas.

Outro conceito importante na AD é o de interdiscurso. O interdiscurso é o conjunto de saberes partilhados dentro de uma sociedade. Os indivíduos dessa sociedade já se acostumaram tanto com um interdiscurso que não conseguem associá-lo com determinada origem histórica. Para o sujeito, o interdiscurso "sempre" existiu.

A existência do interdiscurso e o assujeitamento dos sujeitos provocam o que Pêcheux convencionou chamar de "esquecimento $n^{\circ} 1$ ". Ao comunicar, os indivíduos não se dão conta de que são ideológicos. Esse apagamento da memória de que o discurso enunciado já existia antes do indivíduo o enunciar, faz parecer ao sujeito que é ele o autor do discurso.

Entre as escolhas discursivas possíveis, o sujeito irá selecionar o discurso por meio de um processo de identificação. Quando escolhe entre esses determinados discursos, o sujeito esquece o que motivou sua escolha. Esse é o "esquecimento 
n. 2" da AD. Ele ocorre no intradiscurso, ou seja, dentro dos discursos que compõem a história daquele sujeito específico.

Segundo Souza (2006), o intradiscurso só pode ser compreendido na sua relação com o interdiscurso, o que torna o trabalho do analista do discurso compreender essa articulação de memória e esquecimento presente nas formações discursivas.

Os textos analisados na $\mathrm{AD}$ não devem ser vistos como dados e sim como fatos. Um texto encerra em si um entre os vários discursos de uma formação discursiva em pleno funcionamento. É esse discurso ou discursos que são os dados que o analista irá registrar, não apenas a superfície textual. Por conseguinte, o procedimento da análise deve ocorrer alternadamente entre a discrição linguística e a interpretação discursiva dos textos.

\section{A análise do discurso}

A proposta da AD é a construção de um dispositivo de interpretação que coloque em evidência o que é dito em relação ao que não é dito, o que é dito de outra forma ou em outro lugar (ORLANDI, 2007,p. 59). Não há nela uma procura de uma verdade ou de uma avaliação de um discurso como bom ou mau, mas apenas de evidenciar o mecanismo por trás do funcionamento dos discursos.

Para tanto, será utilizado nessa análise um dispositivo de interpretação específico para o texto "Nunca antes: investir em inclusão digital para promover a inclusão social" publicado no Blog do Planalto. ${ }^{5}$

Pretende-se construir relações entre as palavras escolhidas e as possibilidades descartadas para expressar as mesmas ideias, buscando chegar à materialidade histórica e linguística do texto. É importante avaliar essas escolhas inconscientes do sujeito porque elas indicam a relação que ele manteve com a memória discursiva.

Explicitamos aqui o conceito trabalhado porOrlandi da relação sujeito/autor e discurso/texto: deslocando a noção de autor como proposta por Foucault, Orlandi explica que todo texto, tendo um autor, pode apresentar vários sujeitos diferentes posições - sujeito no mesmo espaço textual. Isso nos leva a noção de incompletude do sujeito e do sentido, proposta pela autora, que leva, por sua vez, à ideia da identidade como movimento, não como estado estático (SOUZA, 2006, p. 103).

Considera-se pertinente também a distinção do dispositivo teórico e analítico da interpretação. Ao passo que o primeiro é o suporte metodológico e teórico já consolidado pela $\mathrm{AD}$, o segundo são esses suportes apropriados pela analista, o que torna sua análise única.

O primeiro passo para executar a análise é sair da superfície do objeto enunciado escolhido para o objeto discursivo em si. A AD realiza tal deslocamento procurando se dar conta dos esquecimentos n. 2 presentes no texto. Segundo Orlandi (2007, p. 65) "[...] construímos, a partir do material bruto, um objeto discursivo em que analisamos o que é dito nesse discurso e o que é dito em outros, em outras condições afetados por diferentes memórias discursivas".

O importante nessa fase é questionar por que aquelas palavras foram utilizadas e não outras. Para balizar a análise escolheu-se questionar o discurso a respeito da inclusão digital que gera os sentidos por trás da superficialidade do texto. Dessa forma será possível compreender ao fim da análise o que pensa o governo federal e suas assessorias de comunicação a respeito da inclusão digital.

Já no título do texto é possível se iniciar o exercício para encontrarmos esquecimentos n. 2: a escolha das palavras "investir" e "promover". "Investir" produz sentidos em relação a práticas financeiras e contábeis de grandes instituições ou o sentido de aplicação de ações enérgicas e decididas?

É interessante recordar que na primeira das possibilidades o investimento está inscrito numa formação discursiva capitalista, por conta de sua presença no jargão do mercado financeiro.

\footnotetext{
${ }^{5}$ Nunca antes: investir em inclusão digital para promover a inclusão social. Blog do Planalto. Brasília, 2010. Disponível em: <http://blog.planalto.gov.br/nunca-antes-investir-em-inclusao-digital-para-promover-a-inclusao-social>. Acesso em: 15 jan. 2011.
} 
A polissemia, processo de geração de novos sentidos, ocorre igualmente com a palavra "promover". A palavra pode produzir sentidos em relação ao fortalecimento de estruturas já existentes, como em "promoção social" ou "promoção dos direitos humanos". Promover desloca uma série de sentidos em relação a ações que visam fortalecer práticas, costumes, hábitos e ideias.

Destaco aqui o sentido de "promoção social" como um dos sentidos consolidados dentro das formações discursivas da esquerda política no Brasil na contemporaneidade.

A escolha dos dois verbos no título indica uma relação da ideia de investimento com recursos digitais e promoção com questões sociais. Ao fazer o exercício parafrástico de análise da escolha dessas palavras, temos "Promover a inclusão digital para investir na inclusão social".

É possível também se utilizar apenas uma das palavras como em "investir em inclusão digital e social" ou "promover inclusão digital e social". Não se trata de analisar aqui as diferenças linguísticas promovidas pela mudança na ordem dessas palavras, mas sim dos sentidos históricos que essas possibilidades deslocam (ORLANDI, 2007, p. 72).

As três frases poderiam ser utilizadas, mas o gesto do sujeito demonstra uma afinidade pela criação de relações diretas entre investir-digital e promover-social. Na primeira relação faz-se presente a ideia de que a inclusão digital tem por fator primordial os recursos de equipamentos, pois podem ser adquiridos com investimentos financeiros. A segunda se inscreve numa tradição política historicamente ligada ao espectro de esquerda, em que os "ganhos capitalistas" se contrapõem à "promoção da sociedade".

As ideias deslocadas por essas palavras caminham para o uso de práticas financeiras que objetivam o fortalecimento dos grupos sociais. Uma análise puramente linguística detectaria aí o deslocamento de ideias circunscritas no jargão empresarial, como "investir" e todas cifras financeiras citadas na matéria. Mas o sentido escolhido indica o uso desses recursos de "capital" a serviço da "promoção" do social.

No segundo parágrafo do texto, o sujeito retoma essas duas ações em "com a meta de reduzir o hiato digital, diminuir o número de excluídos [...] Três frentes foram estabelecidas...". Neste trecho duas escolhas de palavras deslocam ideias para o não dito na materialidade do texto: "hiato" e "três frentes".

$\mathrm{O}$ autor do texto poderia ter utilizado "reduzir a exclusão digital" ou "garantir a inclusão digital" acionando o sentido de solução do problema. Poderia ter sido utilizado ainda "com a meta de solucionar o problema", mantendo o sentido de solucionador. Mas o enunciado diz respeito à palavra biato, mantendo o sentido de diferença, disparidade, lacuna a ser preenchida.

A escolha de "três frentes" chama atenção pelo sentido que ela desloca de ação militar. O texto poderia utilizar "Três soluções simultâneas" ou "Três tipos de ações foram tomadas", mas a utilização de "três frentes" aciona o sentido de haver uma luta em que exigiu "três frentes de batalha". Mas que luta é esta?

Apenas no quinto parágrafo essa questão pode ser evidenciada. Ela aparece no trecho "O acesso à tecnologia não pode ser um privilégio das classes sociais mais favorecidas". O parágrafo poderia ter continuado sem perder sentido com "o acesso a tecnologia deve ser um privilégio de todos" ou "não pode ser restrito aos privilegiados que podem pagar".

Entretanto a escolha das palavras remete a uma memória discursiva marxista. Nesse discurso, há uma luta de classes em que apenas a mais favorecida tem acesso à tecnologia. Esse sentido inclusive completaria o trecho de "três frentes" por se tratar de uma "luta de classes". É a formação discursiva de matriz política de esquerda já citada.

Ao longo da análise foram percebidos outros trechos em que a formação discursiva marxista funciona produzindo sentidos. Um exemplo é: “ter acesso à internet de qualidade era considerado um luxo de poucos" e "para melhorar as condições de vida dos mais pobres", significando que os benefícios serão dirigidos apenas para uma classe social.

A inclusão digital está circunscrita aqui como um prolongamento dessa luta. Nela, as classes "necessitadas" contam com o governo para ter acesso a serviços antes restritos às classes privilegiadas. No texto também se encontram outras formações discursivas interessantes para nossa análise.

No primeiro parágrafo está presente o trecho a respeito da inclusão digital que merece ser destacado: "Num mundo em que acesso à tecnologia praticamente se tornou sinônimo de participação efetiva na sociedade". 
A busca pelo não dito aqui se inicia no questionamento da palavra "praticamente". Realizando novamente a operação de paráfrase encontramos várias possibilidades materiais para constituir esse trecho. Era possível simplesmente não utilizar essa palavra, confirmando a ideia - num mundo em que $\mathrm{O}$ acesso à tecnologia se tornou sinônimo [...].

Outra forma possível é a negação a essa informação: "a tecnologia não é sinônimo de participação". A escolha inconsciente por essa palavra indica um meio termo mais próximo do sentido de um "talvez". Essa palavra na superfície linguística indica que a ideia dessas tecnologias serem aplicadas na política não opera de forma pacífica dentro do discurso presente nesse objeto.

Outras marcas discursivas interessantes foi o uso de palavras como "ferramenta de inclusão" no quinto parágrafo e "necessidade do instrumento" no penúltimo parágrafo. Todas essas escolhas poderiam ser substituídas no texto e também tem em comum o fato de pertencerem a um jargão técnico-operacional. Esse jargão indica uma FD de instrumentalização, na qual essas tecnologias têm uma utilidade prática específica.

A FD de instrumentalização corresponde à ideia criticada por Warschauer (2006) de inclusão digital restrita aos recursos de equipamentos ou digitais, em que a presença desses garantiria o uso pleno das novas tecnologias.

Por fim, ainda há uma questão de segmentação. O autor do texto no segundo e no último parágrafo cita: "em que o desenvolvimento das tecnologias da informação" e "há um longo caminho a trilhar rumo à democratização do acesso às tecnologias da informação [...]" (BLOG DO PLANALTO, 2010). A questão que a análise propõe é: por que essas tecnologias são consideradas apenas de informação e não de comunicação?

A própria sigla TIC, muito utilizada nos estudos em cibercultura, designa Tecnologias da Informação e da Comunicação, levando em conta ambas as ações. Esses estudos indicam que o grande potencial da web é exatamente a capacidade dessa tecnologia de permitir a interação multidirecional e multimodal (CASTELLS, 2003).

O processo de informar está vinculado ao sentido de fornecer dados ou informações a terceiros. Por outro lado, comunicar se estende ao sentido de um diálogo, em que ambas as partes são informadas e fornecem respostas com mais dados ao longo do processo. Os sentidos em jogo são diferentes, mas não excludentes. Ainda assim o silenciamento aqui é significativo (ORLANDI, 2007 , p. 83), pois a palavra "informação" apagou a palavra "comunicação".

Tal escolha de palavras marca a formação discursiva do sujeito-autor do texto quanto às questões de inclusão digital, por mais que não esteja explícito na superfície textual. É o discurso em funcionamento. Já analisadas as marcas discursivas e suas formações, torna-se possível pensarmos no funcionamento das diversas formações ideológicas envolvidas no texto.

\section{A título de conclusão: ideologia e esquecimento}

Ao fim da análise intercalada com a materialidade do corpus, constata-se que estão envolvidas no texto diversas formações discursivas. Pudemos identificar pela análise uma FD marxista, uma FD de instrumentalização dos recursos tecnológicos e uma FD que questiona a importância desses para a democracia e para comunicação, sendo restritos apenas à informação dos usuários.

Ao se adotar a tipologia baseada na relação entre os discursos de Orlandi (2007), percebe-se que os discursos marxista e de instrumentalização presentes no texto são autoritários. O sujeito apagou completamente o referente de ambos, impedindo qualquer outra possibilidade de sentido dentro do texto a respeito desses assuntos.

A indecisão do sujeito quanto ao uso das tecnologias para ampliação das discussões políticas se fez presente. Ela se dá por meio de termos de amortecimento ou modalização como "praticamente", que indica a possibilidade de adoção de outros sentidos. O discurso a respeito desse assunto é considerado polêmico, por conter uma relação tensa de disputa pelos sentidos. Esse processo polissêmico é uma ruptura desse processo de significação (SOUZA, 2006, p. 103), que poderia apenas consolidar a certeza do benefício dessa participação para todos os cidadãos.

Outra FD presente no texto é a da tecnologia que apenas informa. Ela consolida ao longo 
da textualidade o sentido de ferramentas apenas para informação e não para comunicação desses cidadãos. É um discurso também autoritário, que apaga o referente e essa possibilidade.

A existência desses discursos dentro da materialidade linguística não é percebida pelo autor ou autores do texto. A ideologia em que estão imersos e que podem em suas histórias pessoais os terem constituídos não possibilita que percebam seu assujeitamento a esses discursos. É o esquecimento n. 1 da AD em funcionamento. A ideologia tem como sua função primeira apagar-se do sujeito.

A presente análise nos revela uma questão fundamental. Os discursos presentes no texto do Blog do Planalto significam a inclusão digital como um processo de igualdade social ideologicamente marxista. As tecnologias de comunicação funcionariam apenas como um instrumento de informação da população brasileira e não de comunicação ou interlocução política. Em última instância, estarão contribuindo instrumentalmente com a questão central desse discurso: a luta de classe.

Esses discursos apagam referências importantes para a cibercultura. Entre estas referências estão a ampliação da democracia e o aprofundamento da liberdade por meio do aumento do ciberativismo (LEMOS; LÉVY, 2010). Para tanto, deve-se perceber as tecnologias digitais não apenas de forma instrumentalizada, mas como recursos inseridos na sociedade para ampliar o potencial comunicativo dessa sociedade.

Essa análise não pretende esgotar todas as possibilidades de discurso dentro do corpus escolhido. Nenhuma análise o faz. A realidade e seu recorte como objeto de reflexão permanecem para futuras abordagens, seja por conta das possíveis mudanças que as formações discursivas venham a sofrer, seja pelo dispositivo teórico/analítico diferente que outro analista possa vir a utilizar.

O trabalho realizado como análise foi o de apenas evidenciar no corpo de determinado texto as formações discursivas e ideológicas que dão sentido a ele. Com essa configuração e escolha teórica foi possível compreender, de determinada forma, o que é a inclusão digital para os responsáveis pelas políticas públicas que a promovem. Porque os sentidos estão sempre além da superfície linguística, metaforizados pela linguagem que, enganosamente, é transparente para o sujeito.

\section{Referências}

ALTHUSSER, L. Ideologia e aparelhos ideológicos do Estado. In: ZIZEK, S. (Org.). O mapa da ideologia. Rio de Janeiro: Contraponto, 1996. p. 7-38.

BLOG DO PLANALTO. Nunca antes: investir em inclusão digital para promover a inclusão social. Brasília, 2010. Disponível em: <http://blog.planalto.gov.br/ nunca-antes-investir-em-inclusao-digital-para-promover-a-inclusao-social>. Acesso em: 15 jan. 2011.

CASTELLS, M. A galáxia da internet. Rio de Janeiro: J. Zahar, 2003.

CRUZ, R. O que as empresas podem fazer pela inclusão digital. São Paulo: Instituto Ethos, 2004.

FOUCAULT, M. A microfísica do poder. São Paulo: Graal, 2007.

FOUCAULT, M. Arqueologia do saber. Rio de Janeiro: Forense Universitária, 2009.

LEMOS, A.; LÉVY, P. O futuro da internet. São Paulo: Paulus, 2010.

LÉVY, P. Cibercultura. São Paulo: Editora 34, 1999.

MARX, K. A ideologia alemã. São Paulo: M. Fontes, 1998.

ORLANDI, E. P. Análise do discurso: princípios e procedimentos. Campinas: Fontes, 2007.

PÊCHEUX, M. Semântica e discurso: uma crítica à afirmação do óbvio. Campinas: Ed. da Unicamp, 1988.

RIFKIN, J. A era do acesso. São Paulo: Pearson Makron Books, 2001.

SOUZA, S. A. F. de. Conhecendo a análise de discurso: linguagem, sociedade e ideologia. Manaus: Valer, 2006.

WARSCHAUER, M. Tecnologia e inclusão social: a exclusão digital em debate. São Paulo: SENAC São Paulo, 2006.

Recebido: 05/07/2011

Received: 07/05/2011

Aprovado: 08/11/2011

Approved: 11/08/2011 